\title{
Zeytin Ağacı Üzerine Bir Monografi
}

\section{Ahmet Nuri ÖZDAĞ ${ }^{1}$ (D) Fatma KOYUNCU ${ }^{* 2}$ \\ ${ }^{1}$ Adıyaman Sert Kabuklu Meyveler Araştırma Enstitüsü, Adıyaman \\ ${ }^{2}$ Isparta Uygulamalı Bilimler Üniversitesi, Ziraat Fakültesi, Bahçe Bitkileri Bölümü, 32260 ISPARTA}

Öz: Anadolu'dan orijinlenen zeytin ağacı, tarih boyunca Akdeniz havzasında kurulan tüm uygarlıkların temelini oluşturmuş ve Amerika kıtasına kadar uzatmıştır. Bu monografik çalışma zeytin genotiplerinin morfolojik ve pomolojik karakterizasyonunda standardizasyonu sağlamak için faydalanılmak üzere metot oluşturmak amacı ile yürütülmüştür. Bu amaçla "Olive Germplasm-Italian Catalogue of Olive Varieties", "Catailogo Mundial de Variedades de Olivo" ve "Türkiye Zeytin Çeşitleri Kataloğu" yanında UPOV gibi ulusal ve uluslararası tanımlama kriterleri yeniden düzenlenerek yöntemler bileşkesi oluşturulmuştur.

Zeytin genotiplerinin morfolojik tanılamasında kullanılması amacı ile bütün bu mevcut katalog kriterleri; a) Pasaport verileri, b) Morfolojik özellikler, c) Fizyolojik özellikler d) Teknolojik özellikler ana başıkları altında detaylandırılarak incelenmiştir.

Anahtar Kelimeler: genotip, morfoloji, pomoloji, tanımlama

\section{A Monography of Olive Tree}

\begin{abstract}
The olive tree originated from Anatolia formed the basis of all civilizations throughout the Mediterranean basin, and extended its branches to America. This monographic study was carried out to creating a method to be used to provide standardization in morphological and pomological characterization of olive genotypes. For this purpose, "Olive Germplasm-Italian Cortalogue of Olive Varieties"; "Catailogo Mundial de Variedades de Olivo"; and "Turkey Olives Catalog"; with, reorganizing the national and international definition criteria like UPOV methods was formed.

All catalog criteria available using for morphological characterization of olive genotypes; a) Passport data, b) Morphological characteristics, c) Physiological characteristics d) Technological features are examined in detail under main headings.
\end{abstract}

Keywords: characterization, genotype, morphological, pomological

\section{GiRiş}

Dünya zeytin üretiminin \%98'i, Akdeniz'e kıyısı olan ülkelerden elde edilmektedir (Pekitkan ve ark., 2011). Zeytinin gen merkezi ve genotipik çeşitliliğe sahip olan ülkemizde bazı çeşitler ön plana çıkarak, sofralık ve yağlık olarak değerlendirilmektedir (Anonim, 2003). Zeytin, çeşitli iklim koşullarında yaşam alanı oluşturan ve genotipik varyasyonlardan dolayı farklı ve zengin kültür çeşitliliğine sahip olan bir türdür. Gerek taze meyvesi gerekse yağı tüketilen zeytin ağacı Oleaceae familyasının Olea cinsine ait Olea europeae L. subsp. europa alt türü içinde yer almaktadır (Anonim, 2020). Lavee (1990), bilinen çeşit, klon ve alt klon sayısının 2000 den fazla olduğunu bildirmekte iken, Therios (2009) zeytinin kültür formu olan Olea europaea türünün 2600'den fazla çeşit içerdiğini ifade etmektedir. Ülkemizde ise 100'ün üzerinde zeytin çeşidi yetiştirilmektedir. Hem yabani formları hemde kültür çeşitleri bakımından bu sayı büyük bir zenginliktir (Çavuşoğlu, 1980).

Birçok zeytin yetiştiricisi ülkede hala keşfedilmemiş ve dağınık halde bulunan, kayıt altına alınmamış geniş zeytin ağacı varlığı mevcuttur (Bartolini ve Petrucelli, 2002; Rallo ve ark., 2014). Bu gen kaynaklarının morfolojik karakterizasyonları hem bilimsel hem de ekonomik açıdan oldukça önemlidir. Zeytin genotiplerinin tanımlanması amacı ile yapılan ülkemizdeki ilk çalışmaları (Uygur, 1966) takiben bu konu üzerindeki çalışmalar farklı ekolojiler ve farklı popülasyonlar üzerinde yürütülmeye devam etmiştir (Barranco ve Alcala., 1992; Barranco ve ark., 1998; Caballero ve Eguren, 1986; Ekinci 2010, Kaymak, 2011, Kaynaş ve ark.,1992; Muzzalupo, 2012; Sadeg, 2014; Sakar ve ark., 2013; Tutar, 2010). Kaya (2006), Aydın yöresindeki çalışmasında Yamalak Sarısı zeytin çeşidinin kimlik bilgilerini, morfolojik ve fizyolojik özelliklerini, "Uluslararası Zeytinyağı Konseyi" tarafından hazırlanan ve diğer zeytinci ülkelerce de kullanılan "World Catalogue of Olive Varieties, (2000)" e göre incelemiştir. Uluslararası Zeytinyağı Konseyi tarafından oluşturulan kriterler de esas alınarak "Türkiye Zeytin Çeşit Kataloğu” oluşturulmuştur (Kaya ark., 2015). Evrenosoğlu ve ark., (2011), Sarıcakaya-Mayıslar (Eskişehir) yöresindeki Gemlik ve Karamürsel Su çeşitlerinde morfolojik özellikleri belirlemek için metot olarak, Canözer (1991)'in "Standart Zeytin Çeşitleri" ve Kaya (2006)' nın "Yamalak Sarısı" ile ilgili çalışmalarından faydalanmışlardır. Muzzalupo (2012) benzer şekilde çalışmasında, İtalya'da tescilli olan 200 çeşidin morfolojik, pomolojik ve fizyolojik olarak tanımlamalarını yaparak çeşit kataloğu oluşturmayı amaç edinmiştir. Gerekli ölçüm ve gözlemler için, "International Union for the Protection of New Varieties of Plants (UPOV)"

Sorumlu Yazar: fatmaoker@gmail.com. Bu çalışma yüksek lisans tez ürünüdür.

Geliş Tarihi: 1 Ağustos 2019

Kabul Tarihi: 28 Nisan 2020 
kriterlerinden faydalanmıştır. Arsel ve Sefer (2010) ve Sakar ve Ünver (2011) Ülkemizde gerek genetik ve Islah çalışmaları ile geliştirilen zeytin çeşitlerinin gerekse genotiplerinin tanımlanmasına yönelik değerlendirme sonuçlarını geniş içerikleri ile toplu şekilde yayımlamışlardır. Zeytin yayılım alanındaki ülkelerin çoğunda morfolojik, pomolojik ve agronomik özellikleri yeterince bilinmeyen çok sayıda zeytin genotipi bulunmaktadır. Ayrıca yerel olarak seçilmiş ve yetiştiriciliği yapılan çeşitlerin, kendi yaşam alanları dışında nasıl bir uyum gösterecekleri de bilinmemektedir (Kaya, 2006). Modern meyvecilikte ilk tesis oluşturma aşamasında, amaca uygun çeşit belirlenmesi oldukça önemlidir. Bu sebeple çeşit özellikleri ile ilgili detaylı bir bilgiye sahip olabilmenin yolu mevcut çeşit tanımlamalarının iyi bir şekilde yapılmasından geçmektedir (Canözer, 1991). Çeşit belirlemelerindeki en büyük sıkıntı daha önceden kayıt altına alınmış bir çeşidin farklı yörelerde farklı isimle başka bir çeşit olarak bilinmesi veya farklı iki çeşidin aynı isimle yetiştirilip aynı çeşit olduğunun sanılmasıdır (Barranco, 1995). Bu kargaşaların, ortadan kaldırılması için çeşitlerin morfolojik, fizyolojik ve pomolojik olarak tanımlanması çok büyük önem arz etmektedir. Bu amaçla; yapılan çalışmalardan derlenerek ülkemizde daha rahat kullanılabilecek bir metodoloji oluşturmak, çeşitlerin bu kriterlere göre tanımlamalarının yapılmasını kolaylaştırmak amacıyla bu çalışma planlanmıştır. Böylece güncel katalog haline getirilerek çeşitlerin tanınabilirliği ve ulaşılabilirliği kolay hale getirilecektir. Bu çalışmada; ülkemizde henüz tanımlaması yapılmamış oldukça fazla yerel çeşitlerin ve genotiplerin varlığı nedeniyle mevcut genetik zenginliğin tanımlanmasına faydalı olacağı kanaati ile bu yeni tanımlama kataloğu geliştirilmiştir.

Bu metodolojik çalışma; "Karaman yöresinde yetiştiriciliği yapılan Çiltopak mahalli zeytin çeşidinin morfolojik ve pomolojik karakterizasyonu" isimli tez çalışması (Özdağ, 2017) sırasında tarafımızdan duyulan çeşit tanımlama kataloğu ihtiyacını karşılamak amacı ile gerçekleştirilmiştir. $\mathrm{Bu}$ amaçla konu ile ilgili yerli ve yabancı bütün kaynaklar taranmıştır. Bu zeytin monografisinin hazırlanmasında "Türkiye Zeytin Çeşitleri Kataloğu (Kaya ve ark., 2015), UPOV (International Union for The Protection of New Varieties of Plants Geneva -Nisan 2010)" kriterleri, “Olive Germplasm-Italian Catalogue of Olive Varieties" Muzzalupo (2012), "Catálogo Mundial de Variedades de Olivo" (Barranco ve ark., 2000) ve "Yamalak Sarısı" (Kaya ve Tekintaş, 2006) çalışmalarından yararlanılmıştır. Dünya'da kullanılan metotlar bileşkesine bazı değişikler ve ilaveler yapılarak, geliştirilmiştir ve güncel tanımlama kriterleri (katalog) çalışması hazırlanmıştır. UPOV'un nitelik kriterlerinde, önceden tanımlaması yapılmış çeşitlere puanlar verilerek, yeni tanımlaması yapılacak çeşidin hangi puana denk geldiğine bakılmıştır. Çeşit tanımlaması, bu sayede mukayese yolu ile kolaylıkla ve daha net bir şekilde yapılmıştır. Fakat UPOV kriterlerinde, tanımlama amacı ile kullanılan örnek zeytin çeşitlerinin, ülkemizdeki tanınırlığı ve yaygınlığı oldukça azdır. $\mathrm{Bu}$ sebeple bu çalışma oluşturulurken, örnek çeşitler Türkiye ulusal çeşitleriyle yeniden yapılandırılmıştır. Zeytin genotiplerinin morfolojik karakterizasonunda kullanılması amacı ile bütün bu mevcut tanımlama kriterleri aşağıdaki ana başlıklar altında incelenmiştir;
A) Pasaport Verileri
B) Morfolojik Özellikler
C) Fizyolojik Özellikler
D) Teknolojik Özellikler

\section{PASAPORT VERILERI}

$\mathrm{Bu}$ ana başlık altında mahalli çeşit/genotip ile ilgili kimlik bilgileri belirlenmektedir.

- Yaygın olarak bilinen ismi

- Bilinen sinonimleri

- Orijini

- Yayılım alanları

- Kullanım amacı (Sofralık, yağlık, sofralık- yağlık)

\section{MORFOLOJiK ÖZELLIKLER}

Mahalli çeşit/genotipin morfolojik özellikleri, tanımlamanın büyük bir bölümünü oluşturmaktadır. Nicel ve nitel ölçümlerle morfolojik olarak tanımlanabilmesi için yaprak, sürgün, meyve, çekirdek, ölçümleri yapılarak kayıt altına alınmalıdır. Morfolojik özelliklere ait incelenecek parametreler aşağıda detaylı olarak sunulmuştur.

\section{Ağaç özellikleri}

-Kuvvet: Ağaç büyüklüğü, tacın hacmi, dalların uzunluğu ve kalınlığı gibi özelliklere gözlem yolu ile üç sınıfta tanımlanmıştır.

-Zayıf: Ürün verme çağındaki ağacın taç hacminin standartlarına göre çok düşük olması, gelişme şartları uygun olduğu durumda dahi düşük bir gelişim sergilenmesidir. Örn., Aşı Yeli.

-Orta: Ağacın, standart boyutlarda bir taç yapısına, standart bir gelişime sahip olmasıdır. Örn., Gemlik.

-Kuvvetli: Ağacın standart ağaç yapısı ve gelişimleri ele alındığında sürgün, taç yapısı, yükseklik, dal kalınlığı ve uzunluğu olarak üstün bir yapıya sahip olmasıdır. Örn., Domat.

Taç yapısı: Ana ve yan dalların dağılımlarına göre ile üç şekilde sınıflandırılmıştır (Şekil 1).

-Sarkık: Ağacın yapısal olarak kısa dal ve dalcıklarının aşağıya doğru bükülmüş olmasıdır. Örn., Çelebi.

-Yayvan: Uzun dallara sahip olup, dalları kalınlaşır. Ürünler dal üzerinde gelişmeye başlayınca dallar ağırlaşıp, taç olarak daha geniş bir alanı kapsar. Bu durum, ağacın ışıktan daha iyi faydalanmasını sağlar. Örn., Çelebi. 


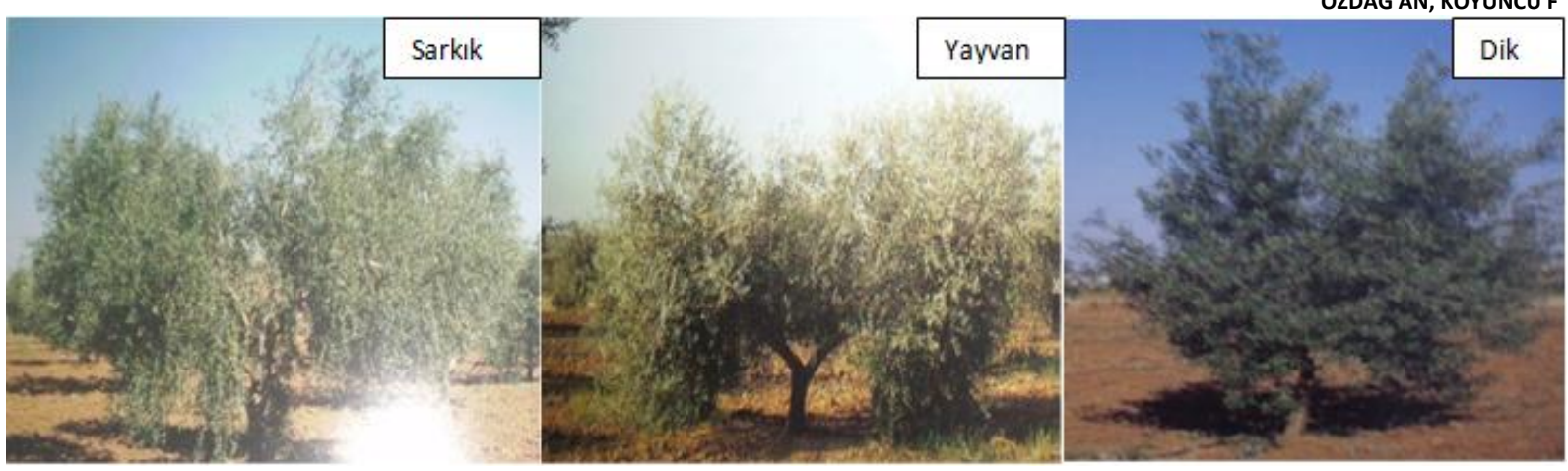

Şekil 1. Zeytin ağacı taç yapısı

-Dik: Bu yapı apikal dormansisi baskın olan ve dik büyüyen dalları tanımlamaktadır. Ağacın taç yapısı ilk olarak konik bir halde bulunurken daha sonradan meyve döneminde silindirik bir hale bürünmektedir. Örn.; Ayvalık.

Taç yoğunluğu: Tacın yeşil aksamı bakımından zenginliğini, ışığın ağaç içine girişini ve yaprak yoğunluğunu gösteren karakterdir. Dal kalınlığı, yaprak boyutları, dal sayısı, boğum aralığı taç yoğunluğunu etkilemektedir. Üç grupta tanımlanmıştır.

-Seyrek: Uzun boğum aralarına sahip, oldukça hızlı büyüyen ve ışık girişi için boşlukları olan çeşitler olarak belirtilir. Örn., Ayvalık.

-Orta: Vegetatif gelişim baskındır ancak boğum arası uzunluğu ve gelişimi yer yer boşluklar oluşturacak şekildedir. Örn., Eşek Zeytini.

-Sık: Boğum araları oldukça kısa, baskın bir dallanma ve yoğun yapraklanma özelliğine sahip çeşitlerdir. Tacın iç kısmı oldukça gölgeli bir haldedir. Örn., Gemlik.

Boğum arası uzunluğu: Ağacın 1.60-1.80 m yüksekliğinde ve tacın iç kısmında bulunan, 8-10 adet meyve dalı üzerindeki iki boğum arası 40 ölçüm yapılmalıdır. Kriter üç grup olarak sınıflandırılmıştır.

-Kısa: $<1 \mathrm{~cm}$

-Orta: $=1-3 \mathrm{~cm}$

-Uzun: $>3 \mathrm{~cm}$

\section{Yaprak özellikleri}

Bu özellikte sayısal olarak; şekil, uzunluk ve genişlik ölçümleri yapılmalıdır. Görsel olarak ise yaprak ayasının boyuna bükümü tespit edilmektedir. Ölçümler için gerekli yapraklar, ağacın 1.60-1.80 m yüksekliğindeki 8-10 adet yıllık sürgünlerinin ortasından en az 40 adet yaprakta yapılan ölçüm ve gözlemler yapılmaktadır.

Şekil (L/W): Yaprak uzunluğunun (L), yaprak genişliğine (W) bölünmesi sonucu elde edilir. Kriter üç şekilde tanımlanmıştır (Şekil 2).

-Eliptik: L/W<4: (Memeli, Tavşan Yüreği) (1)

-Uzun Eliptik: L/W=4-6: (Domat, Gemlik) (2)

-Mızrak: L/W>6: (Yamalak Sarısı) (3)

Uzunluk (L): Yaprak boyu ölçülerek tanımlaması üç gruba göre sınıflandırılmaktadır.


Şekil 2. Zeytin yaprak şekilleri

-Kısa: L<5 cm: (Erkence, Çelebi (Silifke))

-Orta: L=5-7 cm: (Gemlik, Domat)

-Uzun: L>7 cm: (Yamalak Sarısı, Maraş No:7, Kiraz, Eşek Zeytini (Ödemiş))

Genişlik (W): Yaprak boyuna ölçülerek üç grupta sınıflandırılmıştır.

-Dar: $W<1 \mathrm{~cm}$ : (Memeli, Tavşan Yüreği)

-Orta: $W=1-1.5 \mathrm{~cm}$ : (Eşek zeytini, Ayvalık, Domat, Gemlik)

-Geniş: W>1.5 cm: (Yuvarlak Halhalı)

Yaprak ayasının boyuna bükümü: Yaprağın orta çizgisinin büküm doğrultusuna göre tespit edilmektedir. Dört grupta sınıflandırılmıştır (Şekil 3).

-Hiponastik: Orta damar sola bükülmüştür. (1)

-Düz: Orta damar düzdür. (2)

-Epinastik: Orta damar sağa bükülmüştür. (3)

-Helezoninastik: Orta damar spiral şekilde döngülüdür. (4)

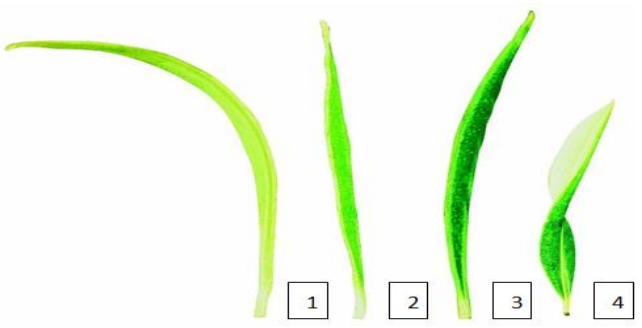

Şekil 3. Yaprak orta damar bükümleri

\section{Çiçek somağı özellikleri}

Ağacın dört yönünden 8-10 adet meyve dalı üzerinden, henüz çiçekler somak halinde iken alınarak 40 adet çiçek somağının uzunluğunun kumpas ile ölçülerek, çiçek sayıları ile birlikte kayıt altına alınmasıdır (Şekil 4). 


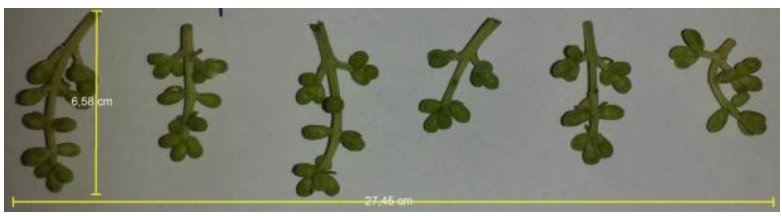

Şekil 4. Zeytin çiçek somağı

Somak uzunluğu: Üç grup halinde tanımlaması yapılmaktadır.

-Kısa: L<25 mm: (Gemlik, Eşek Zeytini)

-Orta: L=25-35 mm: (Ayvalık, Domat)

-Çok: L>35 mm: (Kiraz, Samsun Yağlık)

Çiçek sayısı: Somaklar üzerindeki çiçekler sayılarak (S) belirlenmektedir.

-Az: S<18 Çiçek: (Gemlik, Eşek Zeytini, Domat)

-Orta: $S=18-35$ Çiçek: (Ayvalık)

-Uzun: S>35 Çiçek: (Samsun Yağlık)

Meyve özellikleri

Ağacın her bir yönünde bulunan, çeşit özelliğini yansıtabilecek en az 60 adet meyve üzerinde yapılan ölçümler yapılarak tanımlamaları saptanmalıdır. Bazı özelliklerin tespitinde iki pozisyon esası uygulanmalıdır. A pozisyonu, meyvenin iki ucu, iki parmak arasında kaldığında en yüksek asimetri gösteren pozisyondur. B pozisyonu ise $A^{\prime}$ 'nı $90^{\circ}$ döndürülmesi ile meyvenin en gelişmiş tarafının döndürülmesi ile oluşan pozisyondur. Meyve tanımlanmaları renk dönümünün sonunda olgunluk dönemi başında yapılmalıdır.

Ağırlık (G): Hassas terazi ile belirlenen meyve ağırlığı, dört grupta tanımlanmaktadır

-Küçük: G<2 g: (Girit, Sinop No: 1)

-Orta: $\mathrm{G}=2-4 \mathrm{~g}$ : (Ayvalık)

-ìri: $\mathrm{G}=4-6 \mathrm{~g}$ : (Çilli)

-Çok iri: G>6 g: (Çelebi, Domat)

Şekil (L/W): Meyve boyunun (L), meyve enine (W) oranlaması yolu ile

-Yuvarlak: L/W<1.25: (Ayvalık) (1)

-Oval: L/W=1.25-1.45: (Gemlik) (2)

-Uzun: L/W>1.45: (Domat, Çelebi) (3), şeklinde üç grupta tanımlama gerçekleştirilir (Şekil 5).
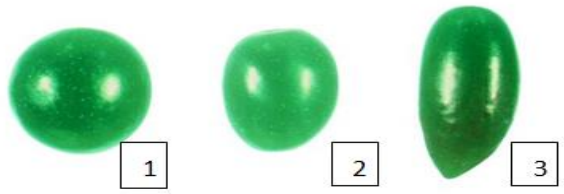

Şekil 5. Zeytin meyvesi şekli

Simetri (A pozisyonu): Meyvenin iki yarısının birbirine eşit olmadığı tarafa göre üç şekilde gruplanır (Şekil 6).

-Simetrik: (Ayvalık, Domat, Büyük T. Ulak) (1)

-Hafif simetrik: (Gemlik) (2)

-Asimetrik: (Eşek Zeytini) (3)

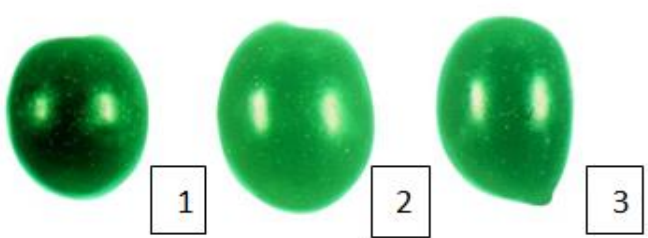

Şekil 6. Zeytin meyvesi simetri durumu

En geniş bulunduğu yer (B pozisyonu): A Pozisyonu $90^{\circ}$ döndürüldükten sonraki kısmının en geniş noktasının üç bölgeden hangisinde olduğuna göre tanımlanmıştır (Şekil 7).

-Sapa Doğru: (Çizmelik) (1)

-Ortada: (Domat, Büyük Topak Ulak) (2)

-Uca Doğru: (Çakır) (3)

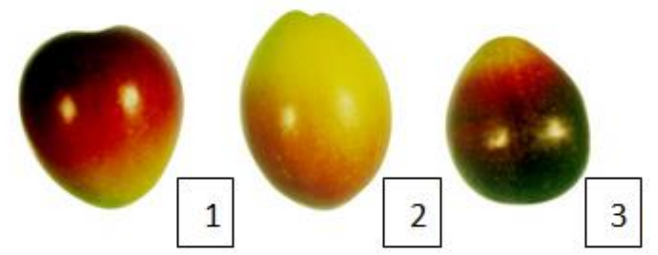

Şekil 7. Meyvenin en geniş bulunduğu yer

Meyve ucu (A pozisyonu): A pozisyonuna göre, meyvenin uç kısmının yuvarlak (oval) veya sivri şekilde olmasına göre görsel olarak tanımlanır (Şekil 8).

-Sivri: (Çekiçte, Memeli, Eşek Zeytini, Uslu) (1)

-Yuvarlak: (Domat, Büyük Topak Ulak) (2)

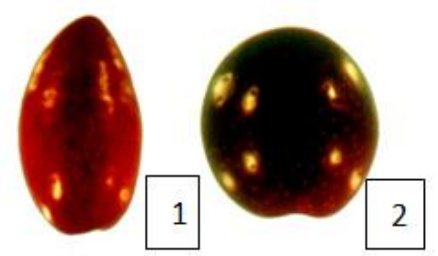

Şekil 8. Meyve ucu durumu

Sap kısmı (A pozisyonu): A pozisyonuna göre şekil olarak yuvarlak veya kesik (düz) bir halde bulunmasına göre;

-Kesik: (Memeli, Gemlik) (1)

-Yuvarlak: (Domat, Büyük Topak Ulak) (2) (Şekil 9).

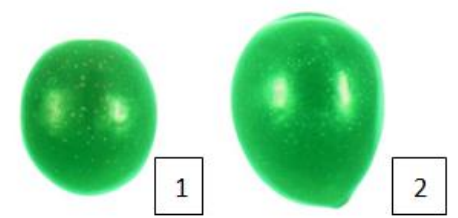

Şekil 9. Meyve sap kısmı 
Meme oluşumu: Zeytinlerin uç kısımlarında meme benzeri bir çıkıntı olup olmaması durumuna göre tanımlanır (Şekil 10),

-Yok: (Domat, Büyük Topak Ulak, Ayvalık) (1)

-Belirgin: (Memecik, Memeli, Çelebi) (2)


Şekil 10. Meyvede meme oluşumu

Lentisel durumu: Meyve kabuk rengi yeşil iken yapılan gözlem ile üzerindeki beyaz beneklerin sayısına göre görsel olarak belirlenir (Şekil 11).

-Az Sayıda: (Domat, Ayvalık, Gemlik) (1)

-Çok Sayıda: (Çilli, Büyük Topak Ulak) (2)


Şekil 11. Meyve lentisel durumu

Lentisel boyutu: Lentisel tanelerinin gözlemsel olarak iri veya ufak olması durumudur. Meyve yeşil iken gözenip tanımlaması yapılmalıdır (Şekil 12).

-Küçük: (Nizip Yağlık) (1)

-Büyük: (Büyük Topak Ulak, Tavşan Yüreği) (2)

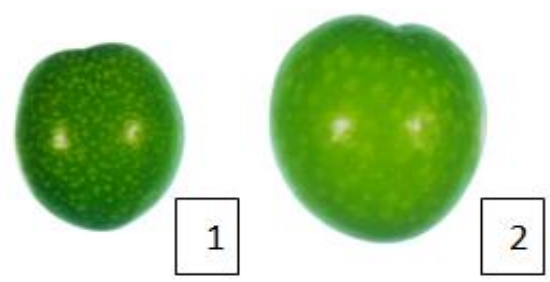

Şekil 12. Meyve lentisel boyutu

Renk değişiminin başladığı bölge: Meyvenin, renk değiştirmeye başladığı bölge gözlem yolu ile tanımlanır.

-Sap kısmından uca doğru

-Orta kısımdan

-Uç kısmından sapa doğru

Çekirdek (endokarp) özellikleri

Değerlendirilmeye alınan en az 60 adet meyvenin, çekirdekleri çıkarılarak ölçüm ve gözlem yolu ile belirlenir. Meyvede olduğu gibi çekirdekte de $A$ ve $B$ pozisyonlarına göre sayısal ve görsel tanımlamaları yapılır.

Ağırlık (G): Hassas terazi ile ölçümü yapılarak dört grup şeklinde tanımlanması yapılmaktadır.
-Küçük: G<0.3 g: (Girit Zeytini, Eğriburun)

ÖZDAĞ AN, KOYUNCU F

-Orta: $\mathrm{G}=0.33-0.45 \mathrm{~g}$ : (Gemlik)

-İri: $\mathrm{G}=0.45-0.7 \mathrm{~g}$ : (Çelebi, Uslu, Domat)

-Çok iri: G>0.7 g: (Yamalak Sarısı)

Şekil (A pozisyonu): Çekirdeğin boyuna (L) ve enine (W) ölçümü yapılarak oranlaması ile dört grup olarak sınıflandırılmaktadır (Şekil 13).

-Yuvarlak: L/W<1.4: (Kilis Yağıık) (1)

-Oval: L/W=1.4-1.8: (Gemlik, Büyük Topak Ulak) (2)

-Eliptik: L/W=0.45-0.7:(Çelebi(Silifke),Yamalak Sarısı, Uslu) (3)

-Uzun: L/W>2.2: (Sarı Ulak, Domat) (4)

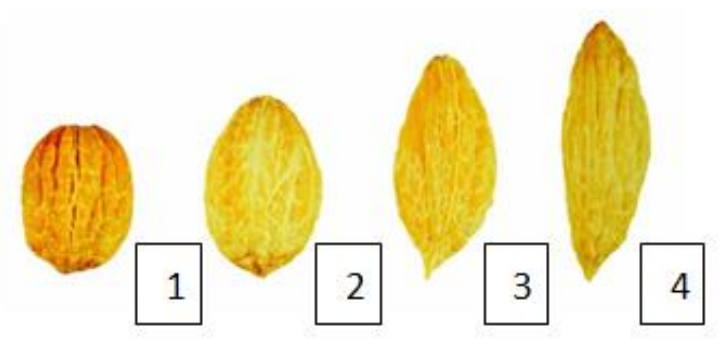

Şekil 13. Çekirdek şekli

Simetri (A pozisyonunda): Çekirdek A pozisyonunda ikiye bölünür. İki parçanın eşit olup olmamasına göre simetrik tanımlanmaktadır.

-Simetrik: (Büyük Topak Ulak, Domat)

-Hafif simetrik: (Gemlik, Memecik)

-Asimetrik: (Uslu, Çelebi)

En geniş noktasının bulunduğu yer (B pozisyonu): B pozisyonundaki en geniş bölgeye göre 3 farklı şekilde tanımlanmıştır.

-Sap kısmına doğru: (Sarı yaprak, Çelebi (Silifke))

-Ortada: (Büyük Topak Ulak, Domat)

-Uca doğru: (Eşek Zeytini, Gemlik)

Çekirdek ucu (A pozisyonu): Çekirdek ucunun oval veya sivri olması durumuna göre görsel olarak tanımlanmıştır (Şekil 14).

-Sivri: (Çelebi, Eşek Zeytini, Ayvalık, Domat) (1)

-Yuvarlak: (Gemlik, Çilli, Büyük Topak Ulak) (2)


Şekil 14. Çekirdek ucu şekli

Sap kısmı (B pozisyonu): Çekirdeğin sap kısmı şekilsel olarak değerlendirilmektedir (Şekil 15).

-Kesik: (Ayvalık, Çakır) (1)

-Sivri: (Çelebi, Domat) (2)

-Yuvarlak: (Gemlik) (3) 

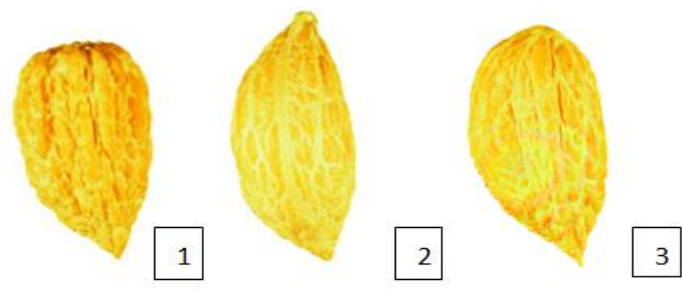

Şekil 15. Çekirdek sap kısmı durumu

Yüzey (B pozisyonunda): Çekirdeğin damar yapısının derin ve yüzeysel oluşuna göre (Şekil 16);

-Pürüzsüz: (Ak Zeytin, Girit Zeytini) (1)

-Pürüzlü: (Yamalak Sarısı, Domat) (2)

-Dikenli: (3), şeklinde tanımlanmaktadır.
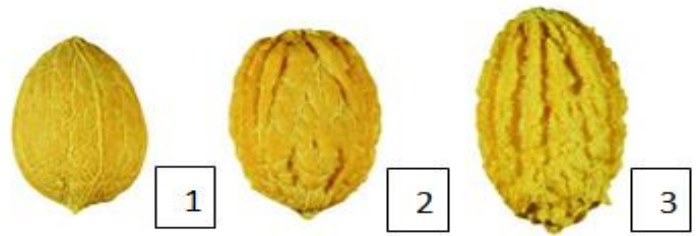

Şekil 16. Çekirdek yüzeyi durumu

Damarların sayısı: En az 60 çekirdek örneğinde damar sayımı yapılmalıdır.

-Az: S<7: (Girit Zeytini, Halhalı)

-Orta: S=7-10: (Çilli, Büyük Topak Ulak)

-Çok: S>10: (Gemlik, Domat)

Uç kısım: Çekirdeğin uç kısmının iğneli veya iğnesiz olması durumuna göre tanımlanmaktadır (Şekil 17).

-ïğneli: (Büyük Topak Ulak) (1)

-iğnesiz: (Sarı Ulak, Yamalak Sarısı) (2)

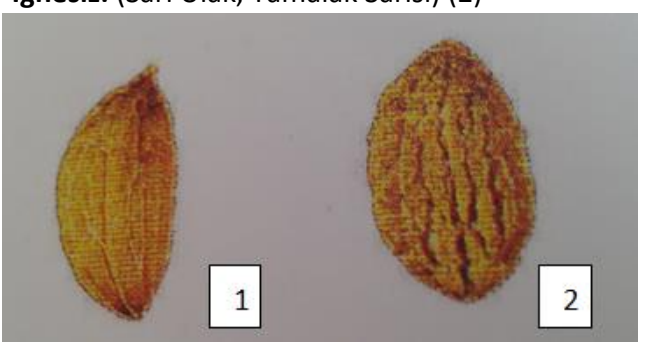

Şekil 17. Çekirdek ucunun iğneli veya iğnesiz olma durumu

\section{FizYOLOJiK ÖZELLIKLER}

Köklenme durumu: Köklendirme denemeleri sonunda çeliklerinin köklenme oranlarına göre 3 farklı sınıfta tanımlanmaktadır.

-Düşük: K<\%20: (Domat)

-Orta: K=\%20-60: (Eşek Zeytini)

-Yüksek: K>\%60: (Yamalak Sarısı, Gemlik)

Fenolojik gözlemler: Ağaçlarda gözlem yapılarak aşağıdaki skalaya göre belirlenmektedir.
-Somağın doğuşu: Yaprak koltuklarında somak sürgününün görülmeye başladığı zaman.

-Çiçeklenme başlangıcı: Çiçeklerin yaklaşık \%5'inin açıldığı zaman.

-Tam çiçeklenme: Ağaçlardaki çiçeklerin yaklaşık \%70'inin açıldığı zaman.

-Çiçeklenme sonu: Çiçeklerin yaklaşık \%70'inin döküldüğü zaman.

-Meyve olgunlaşma dönemi: Çeşidin değerlendirme şekline göre yeşil olum veya siyah olum dönemleri belirlenmektedir.

-Erken: Ekim sonu

-Orta: 15 Kasım-15 Aralık

-Geç: 15 Aralık sonrası

Döllenme biyolojisi: Kendine verimlilik durumunu belirlemek amacıyla; çiçeklenme öncesinde somak halindeki dallarda keseleme yapılmalıdır. Kontrol grubu olarak serbest tozlanmaya bırakılan dallar seçilmelidir. Çiçeklenme sonu keseler çıkartılarak somak üzerinde sayılan çiçek sayısı, meyve tutum miktarına oranlanarak kendine verimli olup olmadığı belirlenmektedir (Mete, 2009; Mete ve ark., 2013; Mete ve Çetin, 2017; Sütçü, 1980). Kaya (2006)'nın kullanmış olduğu sınıflandırmaya göre;

-Kendine verimli: Kendileme ve serbest tozlanmada meyve tutumu düzeyinin çok az bir farklılık göstermesi: (Samanlı, Edincik Su)

-Kendine kısmen verimli: Kendileme yapıldığında, zaman zaman meyve tutumun gerçekleşmesi: (Gemlik, Ayvalık)

-Kendine kısır: Kendilendiği zaman, hiç meyve tutumu olamaması: (Eşek Zeytini, İzmir Sofralık)

\section{TEKNOLOJIK ÖZELLIKLER}

$\mathrm{Bu}$ bölümde tanımlanacak genotipin iyi bilinen çeşit/çeşitlerle benzerlik ve farklılıkları karşılaştırmalı olarak belirtilmelidir. Bu yöntem çeşit adayı zeytinin karakterizasyonunun daha kolay ve verimli yapılmasını sağlayacaktır.

Kilogramdaki Meyve Sayısı (K): 1000 g üründeki meyve adedi (K)

-Çok iri: K<175: (Domat)

-İri: K>176-250: (Büyük Topak Ulak)

-Orta: K>251-335: (Ayvalık, Gemlik)

-Küçük: K>326-421: (Nizip Yağıık)

-Çok küçük: K>422: (Girit Zeytini), olarak değerlendirilmelidir

Et Oranı (\%): Değeri, \%66-85 arasında değişmektedir. Tane meyve ağırlığının (M), tane et ağırlığına (E) olan oranı kayıt altına alınmaktadır (=(E/M)x100).

Etin Çekirdekten Ayrılma Durumu: Tam olum döneminde meyve orta göbeğinden silindirik olarak kesilir. Üst küre alt kürenin tersine çevrilir, dönmenin durumuna göre

-Kolay: (Gemlik)

-Zor: (Eşek Zeytin) olarak iki sınıfta tanımlanmaktadır. 


\section{SONUÇ}

Mevcut metodolojik katalogların yanında belirlediğimiz bu tanımlama kriterleri çalışmasının; özellikle farklı bölgelerde, adapte olmuş mahalli çeşit/genotiplerin morfolojik, pomolojik ve fizyolojik olarak tanımlanması için uygun bir metot olacağı kanaatindeyiz. Bu zeytin monogramının konu ile ilgili araştırma yapacak araştırmacılara, üreticilere hatta tüketicilere faydalı olacağını ön görmekteyiz.

\section{KAYNAKLAR}

Anonim (2003) Zeytin Yetiştiriciliği. Hasat Yayıncılık, ìstanbul. 9-10s.

Anonim (2020) USDA, Agricultural Research Service, National Plant Germplasm System. Germplasm Resources Information Network (GRIN-Taxonomy). National Germplasm Resources Laboratory, Beltsville, Maryland. URL: https://npgsweb.arsgrin.gov/gringlobal/taxonomydetail.aspx?id=400800. Erişim tarihi: 25/04/ 2020

Arsel AH, Sefer F (2010) Zeytincilik Araştırma Enstitüsünde, Geçmişten Günümüze Genetik ve Islah Çalışmaları. Zeytin Bilimi 1 (1):39-42.

Bartolini R, Petrucelli G (2002) Classification, Origin, Diffusion and History of the Olive. In: Tindall HD (eds), Food and Agriculture Organization, Rome, 3-74.

Barranco D, Alcala RA (1992) Prediction of Flowering Time in Olive for the Cordoba Olive Collection. Universidad de Córdoba, Córdoba/Isspanya. Hortscience 27(11):1205-1207.

Barranco D. (1995). The Choice of Varieties in Spain. Olivae. 59:54-58.

Barranco D, Toro CD, Rallo L. (1998) Epocas de Maduracion de Cultivares de Olivo en Cordoba. Invest. Agr.: Prod. Prot. Veg. Vol. 13 (3): 359-368.

Barranco D, Cimato A, Fiorino P, Rallo L, Touzani A, Castaneda C, Serafini F, Trujillo I (2000) Catálogo Mundial de Variedades de Olivo. Internatiol Olive Oil Council, Madrid/İspanya. 1-27s.

Caballero JM, Eguren J (1986) Agronomic Chacractirestics of a World Collection of Olive Cultivars. Olea. 17: 77-83.

Canözer Ö (1991) Standart Zeytin Çeşitleri Kataloğu. Zeytin Araştırma Enstitüsü. Bornova/İzmir. 9-106.

Çavuşoğlu A (1980) Ege Bölgesinde Belli Başlı Yerli ve Yabancı Zeytin Çeşitlerinin Pomolojik Özellikleri Üzerine Araştırma. Araştırma Özetleri (1969-2009). Zeytin Araştırma Enstitüsü, Bornova/İzmir 107s.

Ekinci E (2010) Gökçeada Zeytininin Önemli Zeytin Çeşitleriyle Morfolojik, Pomolojik ve Genetik Özellikler Bakımından Karşılaştırılması. Çanakkale Onsekiz Mart Üniversitesi Fen Bilimleri Enstitüsü Yüksek Lisans Tezi, Çanakkale.

Evrenosoğlu Y, Turhan E, Yılmaz C, Baykul A (2011) Eskişehir-Sarıcakaya Bölgesinde Zeytin (Olea europea) Yetiştiriciliği ve Bazı Zeytin Çeşitlerinde Pomolojik Özelliklerin Belirlenmesi. Ulusal Zeytin Kongresi 22-25 Şubat 2011, 226-231, Akhisar/Manisa.

Kaya H (2006) Aydın Iilinde Yetiştirilen "Yamalak Sarısı" Mahalli Zeytin Çeşidinin Fenotipik Özelliklerinin
Tanımlanması. Yüksek Lisans Tezi, Adnan Menderes Üniversitesi Fen Bilimleri Enstitüsü, Aydın.

Kaya H, Tekintaş FE (2006) Aydın ilinde Yetiştirilen Yamalak Sarısı Mahalli Zeytin Çeşidinin Fenotipik Özelliklerinin Tanımlanması. Adnan Menderes Üniversitesi Ziraat Fakültesi Dergisi. 3(2): 69-76.

Kaya $H$, Sefer $F$, Mete $N$, Çetin Ö, Hakan $M$, Şahin $M$, Güroğlu U, Uluçay N, Veral GV (2015) Türkiye Zeytin Çeşit Kataloğu. Zeytin Araştırma Enstitüsü Müdürlüğü, ISBN: 978-605-9175-04-3. Bornova/Izmir. 197s.

Kaymak H (2011) Şanlıurfa İli Osmanbey Yerleşkesi'nde Bulunan Zeytin Tiplerinin Bazı Özelliklerinin Belirlenmesi. Yüksek Lisans Tezi, Harran Üniversitesi Fen Bilimleri Enst. Bahçe Bitkileri. Şanlıurfa.

Kaynaş N, Sütçü AR, Fidan AE (1992) Marmara Bölgesi Zeytin Çeşitlerinin Pomolojik Özellikleri Üzerine Çalışmalar. Bahçe. 21(1-2):31-38.

Lavee S (1990) Aims, Methods and Advances in Breeding of New Olive (Olea europaea L.) Cultivars. Acta Horticulture (286): 23-36.

Mete N (2009) Bazı Zeytin Çeşitlerinin Döllenme Biyolojisi Üzerine Araştırmalar. Yüksek Lisans Tezi, Ege Üniversitesi Fen Bilimleri Enstitüsü, İzmir.

Mete N, Mısırlı A, Çetin Ö (2012) Determining the Biology of Fertilization and Pollinators in Some Olive Cultivars. Proceedings of the 4th International Conference on Olive Culture and Biotechnology of Olive Tree Products. 69-74.

Mete N, Çetin Ö (2017) Kilis Yağlık Zeytin Çeşidinde Döllenme Sorunun Araştırılması. Harran Tarım ve Gıda Bilimleri Dergisi. 21 (4):376-384.

Muzzalupo I (2012) Italian Catalogue of Olive Varieties. Intech, Italy.

Özdağ A.N. 2017. Karaman Yöresinde Yetiştiriciliği Yapılan Çiltopak Zeytin Çeşidinin Fenolojik Morfolojik Ve Pomolojik Özelliklerinin Belirlenmesi. Yüksek Lisans Tezi, Süleyman Demirel Üniversitesi Fen Bilimleri Enstitüsü, Isparta.

Pekitkan GF, Qabatty A, Alayunt F, Evcim Ü (2011) Zeytin Hasat Makineleri Üzerinde Bir Araştırma. Ulusal Zeytin Kongresi. 22-25 Şubat 2011, Akhisar/Manisa, 36.

Rallo L, Barranco D, Trujillo I, Ojeda MA, Urdiroz NM, Potter D, Diez MC (2014) Identification of The Worldwide Olive Germplasm Bank of Córdoba (Spain) Using SSR and Morphological Markers. Tree Genetics\& Genomes . 10 (1): 141-155.

Sadeg SA (2014) Morphological and Molecular Characterization of Libyan Olive, Olea europaea L., Cultivars (42 Local and 16 Wild Type) in Comparison to 41 Introduced (World) Cultivars. Doktora Tezi, Colorado State University IV-43, Colorado/USA

Sakar E, Ünver H (2011) Türkiye'de Zeytin Yetiştiriciliğinin Durumu ve Ülkemizde Yapılan Bazı Seleksiyon ve Adaptasyon Çalışmaları. Harran Üniversitesi Ziraat Fakültesi Dergisi.15 (2): 19-25.

Sakar E, Çelik M, Ergül A, Ulaş M, Ünver H, Ak BE, Özkaya TM (2013) Şanlıurfa ili Zeytin Gen Kaynaklarının Morfolojik, Pomolojik ve Yağ Asitleri Kompozisyonları ile SSR'a Dayalı Moleküler Karakterizasyonu. 
Süleyman Demirel Üniversitesi Ziraat Fakültesi Dergisi $8(2): 98-110$.

Sütçü AR (1980) Gemlik Zeytininin Döllenme Biyolojisi Üzerine Araştırmalar. Uzmanlık Tezi. Ege Üniversitesi Ziraat Fakültesi, İzmir.

Therios I (2009) Olive. CAB International, UK. ISBN-13: $9781845934583,399$.
Tutar M (2010) Erkence Zeytin Çeşidinde Farklı Tiplerin Belirlenmesi. Ege Üniversitesi, Fen Bilimleri Enstitüsü, Doktora Tezi. Bornova/ízmir.

UPOV TG/99/4 (proj.3) (2010) UPOV (International Union for The Protection of New Varieties of Plants Geneva) Olive Kriteri-18.11.2010. OPUV, Geneva/Isviçre.

Uygur ÇE (1966) Fırat Vadisi Zeytin Çeşitleri. Zeytin Dergisi. 3 (24): 155-159. 